\title{
FUNGSIONALISASI JABATAN PENGHULU DAN PENGARUHNYA TERHADAP KINERJAKUA KECAMATAN DI KOTA MANADO
}

\author{
Syarifuddin \\ Institut Agama Islam Negeri Manado, Manado, Indonesia \\ syarifuddin@iain-manado.ac.id
}

\begin{abstract}
The existence of the chief as an official in the government has existed since the existence of the Islamic kingdom both on Java and outside Java, including in the Dutch colonial government. currently the head of the government based on the ministerial regulation on the utilization of state apparatus number 26 in 2005 has been determined as a functional position according to government regulation Number 16 of 1999 concerning functional positions of civil servants. The tasks of the headman in relation to the application of Islamic teachings and Shari'a in the field of marriage are not just a ceremonial event, but also as a means of manifesting the strictness of a Muslim and unifying the sacred bonds of inner and outer relations between a man and woman. therefore the tasks and roles of the peghulu are considered very important. This paper will discuss the functionalization of the position of the chief and its influence on the performance of the KUA. This study took a research study in KUA Sub-District throughout Manado. The results of the study were that the researchers found that KUA resources in Manado in general still had to be evaluated, because the staff were mostly women, the number of employees was still minimal and the educational background was mostly not S1. Whereas according to the rules, one KUA has 7 or 6 staff but in this city of Manado one KUA only has two or three staff. In addition to the implementation of KUA activities, the budget is still attached to the Department office so that all activities carried out are less effective.
\end{abstract}

Keywords:Penghulu, KUA Manado, Functionalization, Islamic Shari'a.

Abstrak. Keberadaan penghulu sebagai pejabat dalampemerintahantelahadasejakadanyakerajaan Islam baik di Jawa maupun luar Jawa termasuk pada pemerintahan kolonial Belanda. Saat ini penghulu berdasarkan peraturan menteri pendayagunaan aparatur negara nomor: 26 tahun 2005 telah ditetapkan sebagai jabatan fungsional sesuai peraturan pemerintah Nomor 16 Tahun 1999 tentang jabatan fungsional pegawai negeri sipil. Tugas-tugas penghulu berkaitan dengan penerapan ajaran dan syariat agama Islam dibidang pernikahan tidak sekedar sebuah acara seremonial, melainkan juga menjadi sarana perwujudan ketatan seorang muslim dan pemersatu ikatan suci lahir batin antara seorang pria dan wanita. Oleh karena itu tugas dan peran peghulu dirasa sangat penting. Tulisan ini akan membahas tentang fungsionalisasi jabatan penghulu dan pengaruhnya terhadap kinerja KUA. Penelitian ini mengambil studi penelitian di KUA Kecamatan se-kota Manado. Hasil dari penelitian adalah peneliti menemukan masalah bahwa sumberdaya KUA yang ada di kota Manado pada umumnya masih ada yang perlu dievaluasi, karena para stafnya kebanyakan perempuan, jumlah pegawainya masih minim dan latar belakang pendidikan kebanyakan bukan S1. Sedangkan menurut aturan yang ada satu KUA memiliki 7 atau 6 orang staf tetapi di kota Manado ini satu KUA hanya memiliki dua atau tiga orang staf. Selain itu untuk pelaksanaan kegiatan KUA, anggaran masih 
melekat dengan kantor Departemen sehingga segala kegiatan yang dilakukan kurang efektif.

Kata Kunci:Penghulu, KUA Manado, Fungsionalisasi, Syariat Islam.

\section{Pendahuluan}

Secara filosofis agama mempunyai kedudukan dan peranan yang sangat pentingdan strategis, terutama sebagai landasan spiritual, moral dan etika dalam pembangunan nasional. Agama sebagai sistem nilai seharusnya dipahami dan diamalkan oleh setiap individu, keluarga, masyarakat serta menjiwai kehidupan berbangsa dan bernegara. Oleh karena itu, pembangunan agama perlu mendapat perhatian besar baik yang berkaitan dengan penghayatan dan pengalaman agama, pembinaan pendidikan agama maupun pelayanan kehidupan beragama.

Berkenaandenganitu, maka arah kebijakan pembangunan agama sebagaimana tertuang dalam rencana pembangunan jangka menengah (RPJM) 2004-2009 adalah memantapkan fungsi, peran, kedudukan agama sebagailandasan moral, spiritual dan etika penyelenggaraan Negara serta mengupayakan agar segala perundangundangan tidak bertentangan dengan moral agama-agama yang dianut masyarakat Indonesia.

Kantor Urusan Agama (KUA) Kecamatan berdasarkan pasal 2 KMA No. 517 Tahun 2001 tentang penataan organisasi KUA Kecamatan, bertugas melaksanakan sebagian tugas kantor departemen Agama kabupaten / kota di bidang urusan agama Islam dalam wilayah kecamatan. Sehubungan dengan tugas tersebut maka KUA kecamatan mempunyai beberapa fungsi, yaitu melaksanakan pencatatan nikah dan rujuk, mengurus dan membina masjid, zakat, wakaf, baitul mal dan ibadah social, kependudukan dan pengembangan keluarga sakinah sesuai kebijakan yang ditetapkan Dirjen Bimas Islam dan Penyelenggaraan Haji berdasarkan peraturan perundangundangan yang berlaku.

KUA Kecamatan di wilayahkota Manado, sebagaimana KUA-KUA kecamatan di daerah lain tidak lepas dari pemberlakuan peraturan pemerintah tentang petunjuk pelaksanaan jabatan fungsional penghulu tersebut. Kepala kantor wilayah departemen agama 
Propinsi Sulawesi Utara, Sejak digantinya peraturan MENPAN No. 42 Tahun 2004 oleh peraturan MENPAN No. 62 Tahun 2005 tentang jabatan fungsional penghulu dan angka kreditnya, telah mengumpulkan seluruh kepala KUA se Propinsi Sulawesi Utara untuk diberikan penjelasan perihal perubahan peraturan MENPAN tersebut khususnya mengenai jabatan fungsional penghulu berikut ketentuan passing pejabat fungsional penghulu. Lantaranperaturantersebut, tidakseluruhkepala KUA Kecamatan di kota Manado dapatdiinpassing, karena tidak terpenuhinya kriteria pendidikan minimal bagi jabatan penghulu.

Untuk mengetahui dan menelaah lebih jauh pengaruh fungsionalisasi jabatan penghulu terhadap kinerja KUA Kecamatan di kota Manado, maka perlu diadakan penelitian.

\section{HasilPenelitiandanPembahasan}

\section{Struktur Organisasi}

Tiap-tiap organisasi atau badan usaha dalam bentuk bagaimanapun pada dasarnya harus mempunyai struktur organisasi.Struktur organisasi adalah kerangka kerja sama atas dasar pembagian kerja didalam organisasi. Pembagian kerja itu menentukan wewenang, tugas dan kegiatan orangorang dalam rangka kesatuan arah dan tujuan tersebut diperlukan koordinasi, melalui kerjasama hubungan kerja yang serasi sehingga diperoleh kesatuan gerak dan tindak dalam usaha pencapaian tujuan organisasi.

Sebagai suatu kerangka hubungan antara bidang-bidang serta wewenang dan tanggung jawab yang berhubungan dengan peranan suatu bagian. Hubungan-hubungan antara bagianbagian dapat menunjukan adanya kelurusan kerjasama dengan garis yang menghubungkan bagian tertentu dengan lebih tinggi ataupun lebih rendah akan memperlihatkan adanya tanggung jawab dan wewenang yang dilimpahkan.

Berdasarkan uraian di atas, struktur organisasi tidak lepas dari pada:

a. Pembagian Pekerjaan

b. Pembagian wewenang dan tanggung jawab

c. Gambaran tentang bagaimana kegiatan dikoordinasikan dala mencapai sasaran

d. Gambaran tentang luasnya suatu organisasi.

Dalam hubungan dengan masalah kepegawaian, struktur organisasi menyangkut bagaimana mendapatkan 
tenaga yang baik kualitasnya, sehingga dikerjakan dapat berlangsung menurut proses yang direncanakan. Atas dasar pengertian ini, maka penulis akan mengemukakan susunan organisasi Kantor Departemen Agama Kota Manado.

Berdasarkan Keputusan Menteri Agama Republik Indonesia Nomor 373 tahun 2002 tentang organisasi dan tata kerja Kantor Wilayah Departemen Agama Propinsi, Kantor Departemen Agama Kabupaten / Kota dan Balai Pendidikan dan Pelatihan Pegawai Teknis Keagamaan Departemen Agama, Kantor Depertemen Agama Kota Manado termasuk tipologi II-0.

Susunan Organisasi Kantor Departemen Agama Kota Manado adalah Sebagai berikut :

a. Sub Bagian Tata Usaha;

b. Seksi Urusan Agama Islam dan Penyelenggaraan Haji;

c. Seksi Madrasah dan Pendidikan Islam pada Sekolah Umum;

d. Seksi Pekapontren, PENAMAS dan Pemberdayaan Mesjid;

e. Seksi Bimbingan Masyarakat Kristen;

f. Penyelenggaraan Zakat dan Wakaf; g. Penyelenggaraan Bimbingan Masyarakat Katolik;

h. Penyelenggara Bimbingan Masyarakat Hindu dan Budha;

i. Kelompok Jabatan Fungsional.

Jabatan Fungsional yang menjadi perangkat dan mendukung pelaksanaan tugas kantor Departemen Agama Kota Manado adalah sebagai berikut:

1). Perencana

2). Arsiparis

3). Guru

4). Pengawas Pendidikan

5). Penghulu

6). Penyuluh Agama

\section{Kedudukan, TugasdanFungsi}

Kantor Departemen Agama Kabupaten / Kota adalah Instansi Vertikal Departemen Agama yang berada dibawah dan bertanggung jawab langsung kepada kepala kantor Wilayah Departemen Agama Provinsi.

Dalam Keputusan Menteri Agama Republik Indonesia Nomor : 373 tahun 2002 di sebutkan bahwa "kantor Departemen Agama Kabupaten/Kota mempunyai tugas melaksanakan tugas pokok dan fungsi Departemen Agama dalam Wilayah Kabupaten / Kota berdasarkan kebijakan Kepala Kantor 
Wilayah Departemen Agama Provinsi dan Peraturan yang berlaku.

Dalam Melaksanakan tugas tersebut, Kantor Departemen Agama Kabupaten / Kota menyeelenggarakan fungsi :

a. Perumusan Visi, misi dab kebijakan teknis dibidang pelayanan dan bimbingan kehidupan beragama di Kabupaten / kota.

b. Pembinaan, Pelayanan dan bimbingan di bidang bimbingan masyarakat Islam, Pelayanan haji dan umrah, pengembangan zakat dan wakaf, pendidikan agama dan keagamaan, pondok pesantren,pendidikan agama Islam pada masyarakat dan pemberdayaan mesjid,urusan agama, pendidikan agama,bimbingan masyarakat Kristen, Katolik, Hindu serta Budha sesuai peraturan perundang-undangan yang berlaku;

c. Pelaksanaan kebijakan teknis di bidang pengelolaan admnistrasi dan informasi keagamaan

d. Pelayanan dan bimbingan di bidang kerukunan umat beragama; e. Pengkoordinasian, perencanaan, penegendalian dan pengawasan program.

f. Pelaksanaan Hubungan dengan Pemerintah Daerah, Instansi terkait dan lembaga masyarakat dalam rangka pelaksanaan tugas Departemen Agama di Kabupaten / Kota.

Untuk memberikan pelayanan prima kepada masyarakat khususnya umat Islam, maka kantor Departemen Agama Kabupaten / Kota di bantu oleh Kantor Urusan Agama Kecamatan sebagaimana di jelaskan Pasal 2 KMA No. 517 Tahun 2001 tentang Penataan Organisasi KUA Kecamatan bahwa Kantor Urusan Agama ( KUA ) Kecamatan berdasarkan bertugas melaksanakan sebagian tugas Kantor Departemen Agama Kabupaten / Kota di bidang Urusan Agama Islam dalam wilayah kecamatan.

Sehubungan dengan tugas tersebut maka KUA kecamatan mempunyai beberapa fungsi, yaitu melaksanakan pencatatan nikah dan rujuk, mengurus dan mbina masjid, zakat, wakaf, baitul mal dan ibadah sosial,kependudukan dan pengembangan keluarga sakinah sesuai kebijakan yang dittapkan Dirjen Bimas Islam dan Penyelenggaraan Haji 
berdasarkan peraturan perundangundangan yang berlaku.

\section{Pelayanan KUA Kecamatan}

\section{a. Pelayanan dalam bidang pernikahan}

Masalah pernikahan merupakan salah satu tugas pokok dari KUA kecamatan sebagaimana disebutkan dalam KMA Nomor 517 Tahun 2001, Pasal 2 menjelaskan bahwa KUA mempunyai tugas melaksanakan sebagian tugas Kantor Departemen Agama Kabupaten / kota di bidang urusan agama Islam dalam wilayah kecamatan.

Dengan demikian KUA tidak hanya melayani persoalan nikah dan rujuk, tetapi juga pembinaan produk halal, ibadah sosial, kemitraan umat, wakaf, zakat, kemasjidan, LPTQ, kegiatan lintas sektoral dan bimbingan ibadah haji.

Namun demikian, proses penikahan yang dilayani oleh KUA kecamatan pada umumnya pasangan nikah (calon suami isteri) yang ada dikecamatan tuminting, jika aka melaksanakan akad nikah sebagian besar mereka langsung datang ke pembatu PPN. Semua urusan minta diselesaikan oleh pembantu PPN seperti: surat keterangan untuk menikah dari kelurahan, sedangkan Kartu Keluarga dan foto copy KTP. Fas foto $2 \times 3$ sebanyak 5 lembar diserahkan ke pembantu PPN. Kemudian persyaratan tersebut oleh pembantu PPN diserahkan ke KUA Kecamatan.

Di KUA Kecamatan semua persyaratan di terima oleh staf pelaksanaan KUA, yang kemudian sebelum hari $H$ perkawinan ( minimal 10 hari kerja setelah pemeriksaan), pasangan $\mathrm{n}$ ikah di panggil oleh kepala KUA untuk diberikan penasehatan perkawinan. Perkawinan dapat dilaksanakan di umah calon mempelai perempuan sesuai dengan tanggal dan hari yang telah ditetapkan. Setelah selesai akad nikah dan semua persayaratan telah terpenuhi, maka pasangan nikah langsung diberikan buku nikah ( Kutipan Akta Nikah Model NA).

Jika pasangan calon suami istero langsung datang ke KUA melapor untuk melaksanakan pernikahan di Balai KUA melaporr untuk melaksanakan pernikahan di balai Nikah, maka semua 
persaratan untuk menikah dari kelurahan, kartu keluarga,fotocopy KTP, fas foto $2 \times 3$ sebanyak 5 lembar, semua disiapkan / diurus sendiri oleh calon suami isteri. Situasi seperti ini ( nikah dibalai Nikah) dikenakan biaya sebesar Rp. 30.000,- ( Tiga Puluh Ribu Rupiah). Hal ini sesuai dengan KMA Nomor 2 Tahu 2004 dan PMA Nomor 11 Tahun 2007 ( Wawancara dengan kepala KUA kec. Tuminting dan Kepala KUA Kec. Singkil, tanggal 16 mei 2009.

Adapun mengenai biaya nikah/rujuk yang diadakan di balai nikah sebesar Rp. 30.000,- itu berdasarkan Peraturan Pemerintah Nomor 51 Tahun 2005 dan KMA Nomor 2 Tahun 200, Uang tersebut disetorkan ke Kas Negara.

\section{b. Pelayanan dalam bidang Rujuk}

Dari data yang ada di KUA Kecamatan Tuminting, dapat dikatakan bahwa pasangan rujuk sampai saat ini belum pernah ada. Namun pelayanannya hampir sama dalam proses pelayanan nikah, yaitu di periksa data-data talaknya, mengisi blangko rujuk ke Pengadilan Agama, membawa buku pencatatan Rujuk je pengadilan
Agama. ( Wawancara dengan Kepala KUA Kec. Sario tanggal 26 Mei 2009).

\section{c. Peran Kepala KUA dalam bidang zakat}

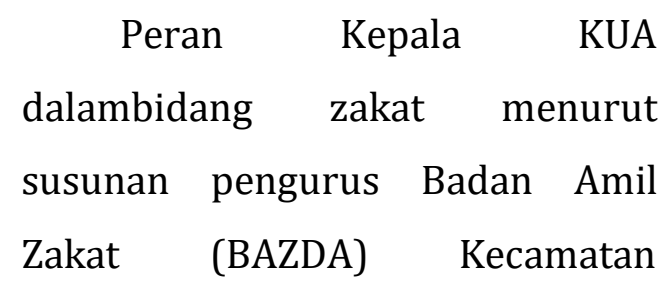
Tuminting 2008/2009, kepala KUA sebagai Pembina masalah zakat.Karena Unit Pengumpul Zakat ada di setiap kelurahan dan mesjid-mesjid, maka pada setiap unit tersebut memiliki panitia masing-masingyang bertugas untuk mengumpulkan dana dari muzakki dan menyalurkan kepada para mustahiq (Wawancara dengan Kepala KUA Kecamatan Tikala, tanggal Juni 2009).

\section{d. Pelayanan dalam bidang wakaf}

Kepala KUA bertugas mencatat, memeriksa data-data status tanah dari wakif, mencatat data-data pribadi wakif dan nazir, membuat Akta Ikrar Wakaf (AIW) dan membuat pengantar ke Badan Pertanahan Negara untuk pengurusan sertifikat wakaf ( Wawancara dengan Kepala KUA 
Kecamatan Mapanget, Tanggal 10 April 2009).

e. Pelayanan

dalam

Bidang

\section{Kemesjidan}

Dalam kegiatan mesjid Kepala KUA seagai pembina keagamaan sekaligus sebagai manajernya, yaitu para Badan Kesejahteraan Mesjid (BKM) dikumpulkan kemudian diberikan pengarahan tentang keagamaan secara langsung dan membina organisasiorganisasi yang ada (Wawancara dengan Kepala KUA Kecamatan Malalayang, tanggal 14 Juni 2009).

\section{f. Pelayanan}

$$
\text { dalam }
$$

bidang

\section{Kesehatan}

Peranan Kepala KUA sebagai pembina dan pemberi penyuluhan terhadap masyarakat setempat tentang TTI dan TT2, masalah KB, Gizi dan sebagainya ( Wawancara dengan Kepala KUA Kec. Wanea, Tanggal 27 April 2009).

\section{g. Pelayanan dalam bidang Keluarga Sakinah}

Peranan Kepala KUA melakukan penyuluhan-penyuluhan tentang Undang-undang Nomor 1 Tahun 1974 tentang Perkawinan, kewajiban sebagai suami Isteri, cara-cara hidup rukun dan damai dalam berkeluarga, memberikan pengertian tentangKeluarga Sakinah ( Wawancara dengan Bapak. Hartono, Penghulu Kec. Tuminting, Tanggal 5 Agustus 2009).

\section{h. Pelayanan Dalam Bidang LP2A}

Peranan Kepala KUA dalam Bidang LP2A sejalan dengan tuntutan dan pekembangan zaman LP2A yang semula berada dibawah Direktorat Penerangan Agama Islam Dirjen Bimbingan Masyarakat Islam dan Urusan Haji, Berdasarkan KA RI NomorTahun 2001 tentang keudukan, tugas, fungsi dan kewenangan, susunan organisasi dan tata Kerja Departemen Agama berpindah menjaadi kewenangan Direktorat Pendidikan Agama Islam Pada Masyarakat dan Pemberdayaan Masjid Dirjen Kelembagaan Agama Islam. Sehubungan dengan itu berdasarkan hasil musyawarah Nasional LP2A tahun 2003 di Kota Palangkaraya Provinsi Kalimantan Tengah di laksanakan pada tanggal 5 juli 2003, Badan P2A menjadi nomenklatur LP2A (Direktur 
Pendidikan Agama Islam pada msayarakat dan Pemberdayaan Mesjid, Jakarta: 2003).

LP2A ini dalam melakukan kegiatannya bekerjasama dengan Majelis Ulama. Sebagai Penasehatnya adalah : Camat dan Majelis Ulama. Sebagai Pembinanya adalah : Kepala KUA, Kepala Dinas Pendidikan Nasional dan 3 Kepala Madrasah Aliyah Negeri ( Wawancara dengan Bapak Irfan Jabli, Penghulu Kecamatan Bunaken).

\section{i. Pelayanan di Bidang Produk Halal}

Masalah produk halal yang selama ini hanya di tangani oleh Majelis Ulama, sebaiknya harus ada dari Departemen Agama Pusat dan Departemen Agama Daerah. Peran KUA dalam produk halal hanya mendata pabrik-pabrik / perusahan-perusahaan tyang ada di wilayahnya. Misalnya pabrik tahu, pabrik tempe, pabrik keripik singkong dan sebagainya. Kemudian pihak KUA melapor ke kantor Departemen Agama. Karena tidak ada tim khusus dari Daerah, maka sulit di tangani dengan baik. (
Waewancara dengan kepala KUA Kec. Wenang, Tanggal 7 Juni 2009).

\section{Pelaksanaan Peraturan Jabatan Fungsional Penghulu}

Respon Pejabat Departemen Agama diantaranya ialah:

a. Kepala Kantor Departemen Agama Manado berpendapat bahwa sebenarnya adanya peraturan Jabatan Fungsional penghulu itu baik, yaitu meningkatkan kualitas tetapistaf KUA yang ada di KUA KUA Kota Manado kebanyakan perempuan ( 19 orang ) dan 5 lakilaki, tetapi dari 5 orang itu hanya 2 yang sarjana sehingga sulit untuk mengikuti aturan tersebut.

b. Kepala KUA berpendapat bahwa adanya peraturan Jabatan fungsional penghulu di tanggapinya merupakan angin yang bagus, paling tidak apa-apa yang mereka lakukan di nilaidan dihargai, jabatan funsional penghargaan lebih baik, penilaian di lihat dari hasil prestasi, sedangkan jabatan struktural atasan maunya begitu, ya kita mengikuti apa maunya, jadi menurut kepala KUAKecamatan Tuminting yang paling 
menguntungkan apa yang kita lihat itulah kita ambil hasilnya.

c. Drs. Abdul Said Ismail menyambut baik perenghargaan pemerintah itu yang diberikan kepada penghulu dengan Jabatan Fungsional sehingga penghulu yang aktif dan memenuhi angka kredit tertentu bisa mencapai golongan IV/c. Namun penghargaan pemerintah dengan memberikan jabatan fungsional penghulu itu di nilai belum dapat di samakan dengan jabatan struktural eselon III/b, seperti camat, karena tugas Kepala KUA dan Penghulu adalah di samping melaksanakan tugas-tugas kepenghuluan, mereka juga harus melaksanakan kegiatan lintas sektoral. Kegiatan lintas sektoral inilah yang memerlukan koordinasi dengan instansi terkait seperti camat, Kapolsek, Koramil dan Lurah. Oleh karena itu menurut beliau menyarankan agar jabatan struktural kepala KUA di naikan sama dengan jabatan struktural Camat. Oleh karena itu menurut beliau jabatan fungsional penghulu ini perlu di sosialisasikan lebih dulu, sebab tidak mustahil dengan jabatan fungsional penghulu justru akan memberatkan penghulu itu sendiri didalam mengurus kenaikan pangkatnya, karena belum semua penghulu memiliki latar belakang pendidikan S1 dan kemampuan penghulu mengumpulkan angka kredit itu di nilai masih rendah terutama di Wilayah Indonesia bagian timur.

Faktor Pendukung dan Penghambat

Faktor yang mendukung
pelaksanaan jabatan fungsional
penghulu agar dapatberjalanlancar,
antara lain:

a. Menggalakkan sosialisasi tentang jabatan fungsional penghulu tersebut;

b. Meningkatkan Sumber Daya Manusia KUA;

c. Memenuhi sarana dan Prasarana KUA;

d. Anggaran untuk kegiatan KUA perlu di tinjau kembalikarena selama ini masih melekat pada kantor Departemen Agama;

e. Menambah Personil KUA kalau kelima hal tersebut telah terpenuhi, maka pelaksanaan jabatan fungsional penghulu itu dapat berjalan dengan baik. 
Adapun faktor penghambat antara lain :

a. Sosialisasi jabatan fungsional penghulu secara khusus belum pernah di laksanakan kecuali disisipkan acara tertentu, seperti dalam acara orientasi keluarga sakinah dan oreintasi manajemen KUA;

b. SDM KUA masih rendah dan pegawainya masih sangat minim serta pegawainya kebanyakan perempuan;

c. Anggaran KUA masih melekat pada kantor Departemen Agama sehingga segala kegiatan berjalan kurang efektif;

d. Tunjangan dan angka kredit jabatan funsional penghulu belum jelas.

e. Sarana dan prasarana KUA masih sangat kurang.

\section{Penutup}

Dari hasil penelitian dana pembahasannya dapat disimpulkan sebagai berikut:

1. Sumberdaya KUA yang adadi kota Manado pada umumnya masih ada yang perlu dievaluasi, karena para stafnya kebanyakan perempuan, jumlah pegawainya masih minim dan latarbelakang pendidikan kebanyakan bukan
S1. Sedangkan menurut aturan yang ada satu KUA memiliki 7 atau 6 orang staf tetapi di kota Manado ini satu KUA hanya memiliki dua atau tiga orang staf.

2. Untuk pelaksanaan kegiatan KUA, anggaran masih melekat dengan kantor Departemen sehingga segala kegiatan yang dilakukan kurang efektif.

3. Pelaksanaan kegiatan khusus sosialisasi jabatan fungsional penghulu masih belum optimal. Namun dalam acara-acara seperti keluarga sakinah, orientasi managemen KUA, maka disisipkan atau diinformasikan tentang masalah jabatan fungsional penghulu.

4. Jabatan fungsional penghulu belum optimal. Karena baru 1 orang penghulu yang naik pangkat melalui angka kredit jabatan fungsionalnya.

\section{Daftar Pustaka}

Affandi Mochtar (ed). 1996. Menuju Penelitian Keagamaan dalam Perspektif Penelitian Sosial.. 
Cirebon: Fakultas Tarbiyah IAIN Sunan Gunung Djati.

Ari Arikunto. 2002. Suharsimi, Prosedur Penelitian: Suatu Pendekatan Praktik. PT. Rineka Cipta: Jakarta, EdisiRevisi V 